University of Nebraska - Lincoln

DigitalCommons@University of Nebraska - Lincoln

Publications, Agencies and Staff of the U.S.

Department of Commerce

U.S. Department of Commerce

2002

\title{
Intermittent Turbulence Associated with a Density Current Passage in the Stable Boundary Layer
}

Jielun Sun

National Center for Atmospheric Research

Sean P. Burns

National Center for Atmospheric Research

Donald H. Lenschow

National Center for Atmospheric Research

Robert Banta

NOAA Environmental Technology Laboratory

Rob Newsom

Cooperative Institute for Research in the Atmosphere

See next page for additional authors

Follow this and additional works at: https://digitalcommons.unl.edu/usdeptcommercepub

Part of the Environmental Sciences Commons

Sun, Jielun; Burns, Sean P.; Lenschow, Donald H.; Banta, Robert; Newsom, Rob; Coulter, Richard; Fraiser, Stephen; Nappo, Carmen; Cuxart, Joan; Blumen, William; Lee, Xuhui; and Hu, Xin-Zhang, "Intermittent Turbulence Associated with a Density Current Passage in the Stable Boundary Layer" (2002).

Publications, Agencies and Staff of the U.S. Department of Commerce. 4.

https://digitalcommons.unl.edu/usdeptcommercepub/4

This Article is brought to you for free and open access by the U.S. Department of Commerce at DigitalCommons@University of Nebraska - Lincoln. It has been accepted for inclusion in Publications, Agencies and Staff of the U.S. Department of Commerce by an authorized administrator of DigitalCommons@University of Nebraska - Lincoln. 


\section{Authors}

Jielun Sun, Sean P. Burns, Donald H. Lenschow, Robert Banta, Rob Newsom, Richard Coulter, Stephen Fraiser, Carmen Nappo, Joan Cuxart, William Blumen, Xuhui Lee, and Xin-Zhang Hu 


\title{
INTERMITTENT TURBULENCE ASSOCIATED WITH A DENSITY CURRENT PASSAGE IN THE STABLE BOUNDARY LAYER
}

\author{
JIELUN SUN ${ }^{\star}$, SEAN P. BURNS and DONALD H. LENSCHOW \\ National Center for Atmospheric Research ${ }^{\star \star}$, Boulder, Colorado, U.S.A. \\ ROBERT BANTA \\ NOAA Environmental Technology Laboratory, Boulder, Colorado, U.S.A. \\ ROB NEWSOM \\ Cooperative Institute for Research in the Atmosphere, Fort Collins, Colorado, U.S.A. \\ RICHARD COULTER \\ Argonne National Laboratory, Argonne, Illinois, U.S.A. \\ STEPHEN FRASIER AND TURKER INCE \\ University of Massachusetts, Amherst, U.S.A. \\ CARMEN NAPPO \\ Atmospheric Turbulence and Diffusion Division, Oak Ridge, Tennessee, U.S.A. \\ JOAN CUXART \\ Instituto National Meteorologia, Barcelona, Spain \\ WILLIAM BLUMEN \\ Program in Atmospheric and Oceanic Sciences, University of Colorado, Boulder, U.S.A. \\ XUHUI LEE AND XIN-ZHANG HU \\ Yale University, New Haven, Connecticut, U.S.A.
}

(Received in final form 18 December 2001)

\begin{abstract}
Using the unprecedented observational capabilities deployed during the Cooperative Atmosphere-Surface Exchange Study-99 (CASES-99), we found three distinct turbulence events on the night of 18 October 1999, each of which was associated with different phenomena: a density current, solitary waves, and downward propagating waves from a low-level jet. In this study, we focus on the first event, the density current and its associated intermittent turbulence. As the cold density current propagated through the CASES-99 site, eddy motions in the upper part of the density current led to periodic overturning of the stratified flow, local thermal instability and a downward diffusion of turbulent mixing. Propagation of the density current induced a secondary circulation. The descending motion following the head of the density current resulted in strong stratification, a sharp reduction in the turbulence, and a sudden increase in the wind speed. As the wind surge propagated toward the surface, shear instability generated upward diffusion of turbulent mixing. We demonstrate in detail that the height and sequence of the local thermal and shear instabilities associated with the dynamics of the density current are responsible for the apparent intermittent turbulence.
\end{abstract}

Keywords: Density currents, Intermittent turbulence, Nocturnal boundary layer, Stable surface layer.

$\star$ Also affiliated with PAOS, University of Colorado.

$\star \star$ The National Center for Atmospheric Research is sponsored by the National Science Foundation.

Boundary-Layer Meteorology 105: 199-219, 2002. 


\section{Introduction}

Numerous observational studies have concentrated on documenting unstable boundary-layer structure utilizing Monin-Obukhov (M-O) similarity theory. In contrast, stable boundary layers have been less studied. Intermittent or sporadic turbulence is frequently observed, yet the origin of the intermittency is not well understood (Nappo, 1991; Howell and Sun, 1999; Mahrt, 1999). Mesoscale motions related to turbulence intermittency have been linked to Kelvin-Helmholtz $(\mathrm{K}-\mathrm{H})$ instabilities, gravity waves, and wake vortices (Doran and Horst, 1981; Mahrt and Larsen, 1982; Emanuel, 1983; Etling, 1990). A series of papers based on data from the Boulder Atmospheric Observatory (BAO) focused on interactions between turbulence and gravity waves (Lu et al., 1983; Finnigan et al., 1984; Finnigan, 1988; Einaudi et al., 1989) and between turbulence and solitary-like waves (Cheung and Little, 1990; Einaudi and Finnigan, 1993).

Blumen et al. (1999) analyzed the heat budget in a shallow density current. However, detailed relationships between intermittent turbulence and transient mesoscale motions have not been studied due to lack of simultaneous observations of different vertical and horizontal scales of motions in the nocturnal boundary layer. The Cooperative Atmosphere-Surface Exchange Study-99 (CASES-99), conducted near Leon, Kansas, in October, 1999, provided unprecedented observational coverage of the nocturnal boundary layer (Poulos et al., 2002). In this study, we focus on relationships between turbulence intermittency and a density current that occurred at approximately 0145 UTC on the night of 18 October 1999. The data used in this study are described in Section 2. Detailed relationships between intermittent turbulence and the dynamics of the density current are analyzed in Section 3. A summary is given in Section 4.

\section{Observations and Data Processing}

The CASES-99 data used in this study were collected mainly from the 60-m scaffolding tower $\left(37.648^{\circ} \mathrm{N}, 96.736^{\circ} \mathrm{W}\right)$, and six $10-\mathrm{m}$ Integrated Surface Flux Facility (ISFF) towers, which surrounded the 60-m tower (Figure 1). All these towers were located at the main experimental site and were deployed by the Atmospheric Technology Division (ATD) of the National Center for Atmospheric Research (NCAR). On the 60-m main tower, sonic anemometers (Campbell CSAT and Applied Technologies, Inc.) were mounted at 8 levels $(1.5 \mathrm{~m}, 5 \mathrm{~m}, 10 \mathrm{~m}$, $20 \mathrm{~m}, 30 \mathrm{~m}, 40 \mathrm{~m}, 50 \mathrm{~m}$, and $55 \mathrm{~m}$ ), Krypton hygrometers (Campbell KH-20) at 3 levels $(5 \mathrm{~m}, 20 \mathrm{~m}$, and $55 \mathrm{~m})$, IRGA $\mathrm{H}_{2} \mathrm{O} / \mathrm{CO}_{2}$ open-path IR gas analyzers at 2 levels $\left(20 \mathrm{~m}\right.$ and $40 \mathrm{~m}$ ), an infrared $\mathrm{CO}_{2}$ analyzer (Li-Cor 6251) at 1 level $(5 \mathrm{~m})$, barometers (Paroscientific) at 3 levels $(1.5 \mathrm{~m}, 30 \mathrm{~m}$ and $50 \mathrm{~m})$, prop-vane wind measurements (RM Young Model 9101 Anemometers) at 4 levels (15 m, $25 \mathrm{~m}, 35 \mathrm{~m}$, and $45 \mathrm{~m}$ ), and aspirated Väisälä 50Y Humitter sensors (PRT) for 


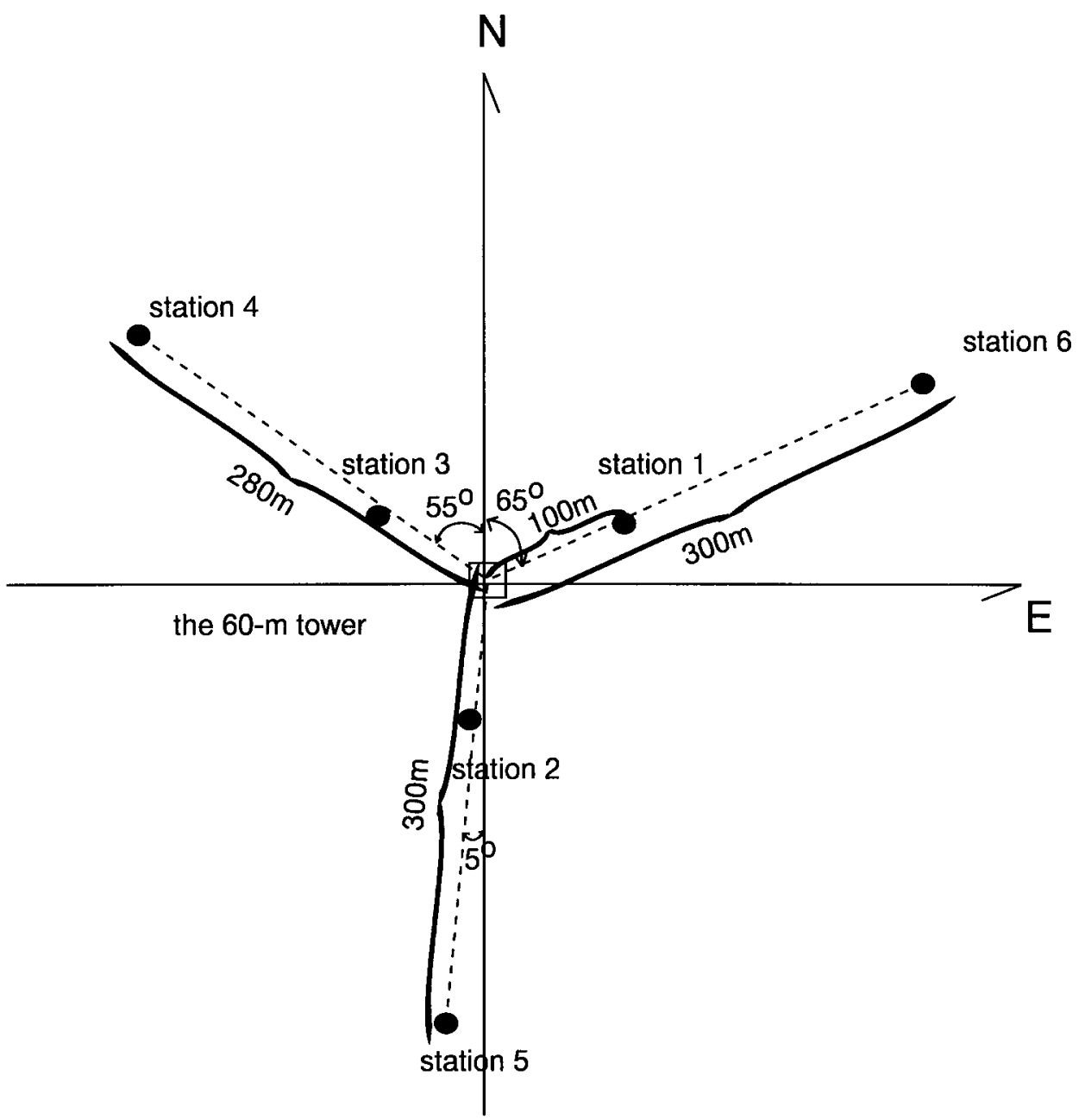

Figure 1. The plan view of the six 10-m ISFF towers and the main 60-m tower.

temperature/humidity measurements at 6 levels $(5 \mathrm{~m}, 15 \mathrm{~m}, 25 \mathrm{~m}, 35 \mathrm{~m}, 45 \mathrm{~m}$, and $55 \mathrm{~m})$. All the above sensors, except the Väisälä temperature/humidity sensors, were mounted on $4 \mathrm{~m}$ booms, pointing to the east. The measurements from the sonic anemometers, Krypton hygrometers, and IRGA $\mathrm{H}_{2} \mathrm{O} / \mathrm{CO}_{2}$ sensor on the 60$\mathrm{m}$ tower were sampled at $20 \mathrm{~s}^{-1}$ and the remaining instruments at $1 \mathrm{~s}^{-1}$. On each ISFF tower, a sonic anemometer and a krypton water vapour sensor were mounted at $5 \mathrm{~m}$, a prop-vane anemometer for wind measurement at $10 \mathrm{~m}$, and a barometer and Väisälä temperature/humidity sensor at $2 \mathrm{~m}$. The sampling rate from the sonic anemometers and krypton water vapour sensors at the ISFF towers was $20 \mathrm{~s}^{-1}$, and the rest of the measurements on the ISFF towers were sampled at $0.2 \mathrm{~s}^{-1}$.

Air temperature was also measured by thermocouples (E-type, Chromel/Constantan, $0.0254 \mathrm{~mm}$ diameter) at 32 levels on the main tower and two 
levels on two adjacent posts (Burns and Sun, 2000). The thermocouple temperatures were recorded at $5 \mathrm{~s}^{-1}$ with a vertical resolution of $1.8 \mathrm{~m}$ on the main tower between $2.3 \mathrm{~m}$ to $58.1 \mathrm{~m}$ height, and also at $0.23 \mathrm{~m}$ and $0.63 \mathrm{~m}$ on two adjacent mini-towers. The absolute thermocouple temperatures compare well with the aspirated air temperatures, and temperature fluctuations compare well with virtual temperatures from the sonic anemometers (Poulos et al., 2002).

The FM-CW (frequency-modulated continuous-wave) radar system, developed by the University of Massachusetts Microwave Remote Sensing Laboratory, is a vertically pointing S-band radar with $2.5-\mathrm{m}$ height resolution within a $3^{\circ}$ beam (Ince et al., 1998). During CASES-99 it operated at a center frequency of 2.735 $\mathrm{GHz}$ corresponding to a wavelength of $0.11 \mathrm{~m}$. The FM-CW radar is sensitive to refractive index gradients and fluctuations at a scale of half the wavelength, or $0.055 \mathrm{~m}$. At microwave frequencies the refractive index depends primarily on humidity and to a lesser extent on temperature.

The High Resolution Doppler Lidar (HRDL), a scanning, coherent Doppler lidar system designed for atmospheric boundary-layer research, was deployed by the Environmental Technology Laboratory (ETL) of the National Oceanic and Atmospheric Administration (NOAA) at a site approximately $1.45 \mathrm{~km}$ south of the $60-\mathrm{m}$ tower. HRDL produces range-resolved measurements of radial velocity (i.e. the component of the wind velocity along the beam) and aerosol backscatter. By scanning in azimuth or elevation, HRDL can map out the wind field over a two-dimensional section of the atmosphere. In this study the most useful scans were vertical-slice scans generated by scanning in elevation at a fixed azimuth. Its velocity precision is $0.1 \mathrm{~m} \mathrm{~s}^{-1}$ for diffuse aerosol returns, and its range resolution is $30 \mathrm{~m}$. The minimum range was $270 \mathrm{~m}$ for this project, and the maximum range, which depends on aerosol concentration, was generally $\sim 2.5 \mathrm{~km}$ in the relatively clean nighttime air of the CASES-99 site. A description of the HRDL system, including design specifications, is given in Grund et al. (2001) and Wulfmeyer et al. (2000), and a more in-depth discussion of its role in CASES-99 is given in Blumen et al. (2001), and in Newsom and Banta (2002).

The Argonne National Laboratory Boundary Layer Experiment (ABLE) Doppler mini-sodar monitored wind profiles from about $10 \mathrm{~m}$ to $200 \mathrm{~m}$ height (Coulter and Martin, 1986). It measures the intensity and Doppler shift of backscattered acoustic energy associated with index of refraction fluctuations, which depend on temperature and humidity fluctuations.

In order to capture the fast temporal variation of the turbulent fluxes, all turbulent fluxes are calculated using perturbations from the 5-min unweighted means. Based on calculations of accumulated turbulent fluxes, the 5-min data sample size captures all the turbulent eddies most of the time. Unlike Einaudi et al. (1989) and Einaudi and Finnigan (1993), in which turbulence was separated from gravity waves, the 5-min data sample size used in this study may occasionally include some wave contributions to fluxes. The 5-min data intervals are carefully chosen to avoid the sudden sharp temperature changes associated with mesoscale disturbances. In 


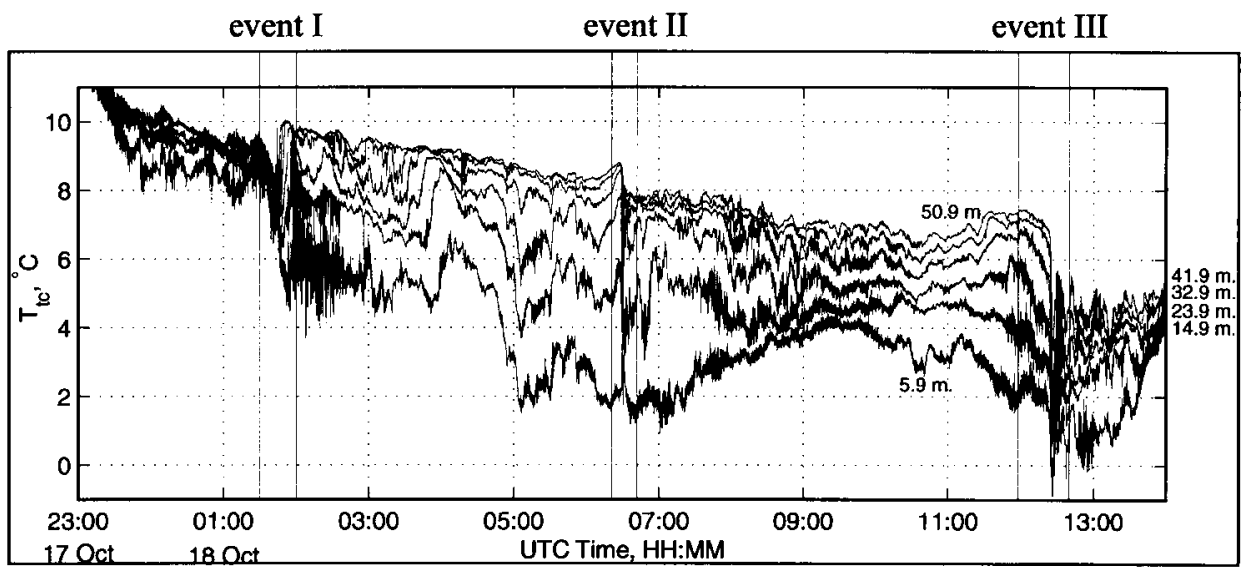

Figure 2. Thermocouple temperatures at selected heights (a subset of the thermocouple measurements) on the night of 18 October 1999.

this study, the Universal Time Coordinated (UTC) is used; therefore, the entire night is within one UTC day. The local standard/daylight saving time is $6 / 5$ hours behind the UTC time.

\section{Turbulence Intermittency and the Density Current}

During the night of 18 October 1999, Intensified Observation Period (IOP)-7, three distinct turbulent events, characterized by large temperature decreases, occurred around 0145 UTC, 0630 UTC, and 1220 UTC, respectively (Figure 2). Intermittent turbulence is clearly evident in the observed vertical velocity fluctuations at 8 levels on the $60-\mathrm{m}$ tower (Figure 3). Strong turbulent mixing was associated with the first and third events, and weak turbulent mixing with the second event when the stratification was maximum for the night. HRDL observations indicated that there was a low-level jet (LLJ) throughout the night. The speed of the LLJ maximum was relatively steady at $7 \pm 1 \mathrm{~m} \mathrm{~s}^{-1}$ at around $200 \mathrm{~m}$ (Figure 4). The wind direction varied from southerly to northerly during the night. In this section, we demonstrate that the first event is a density current and the apparent intermittent turbulent mixing during the passage of the density current is associated with local thermal and shear instabilities introduced by the dynamics of the density current. The other two events during the night will be studied in a subsequent paper.

\subsection{DENSITY CURRENTS}

Density currents (also called gravity or buoyancy currents) can be initiated from distant cold fronts, drainage flows due to ground radiative cooling, or atmospheric mesoscale disturbances (Simpson, 1997). As a density current develops, the fastmoving cold air sweeps across the ground, leading to enhanced turbulence within 


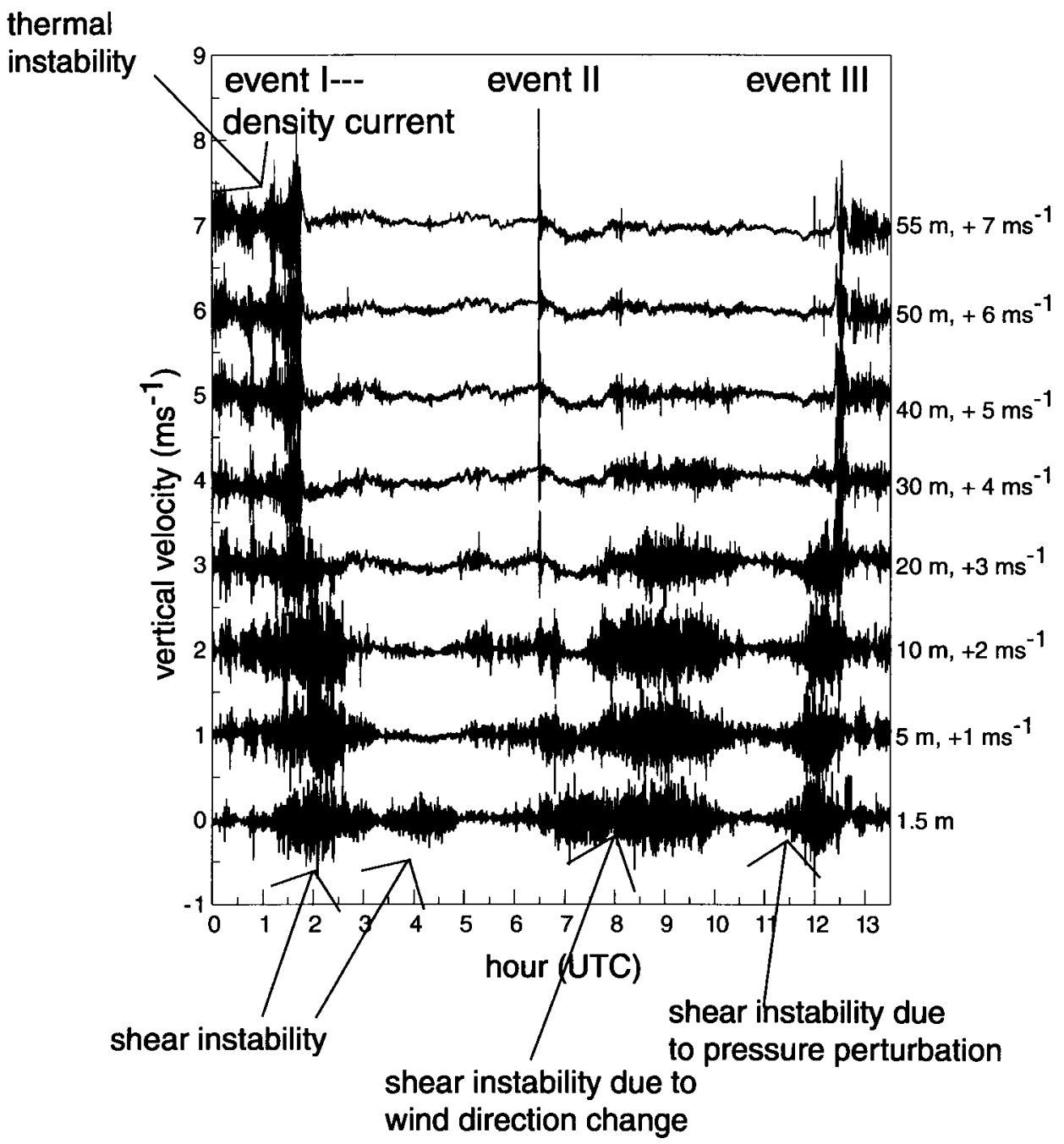

Figure 3. The vertical velocity at 8 levels on the 60 -m tower on the night of 18 October 1999. Starting from $5 \mathrm{~m}$, the value of the vertical velocity is shifted by the amount listed at the right side of each time series. Intermittent turbulence and instabilities that are not associated with event I will be discussed in a subsequent paper.

the density current. The propagation of the density current eventually slows down due to surface drag associated with turbulent mixing (Fulton et al., 1990; Simpson, 1997). As a result, the density current usually forms an elevated leading edge or 'nose'. The head of the density current can extend higher than its tail. Our detailed data analysis of event I demonstrate all these density current features (see the remaining section). Therefore, we will call event I a density current in this study. 


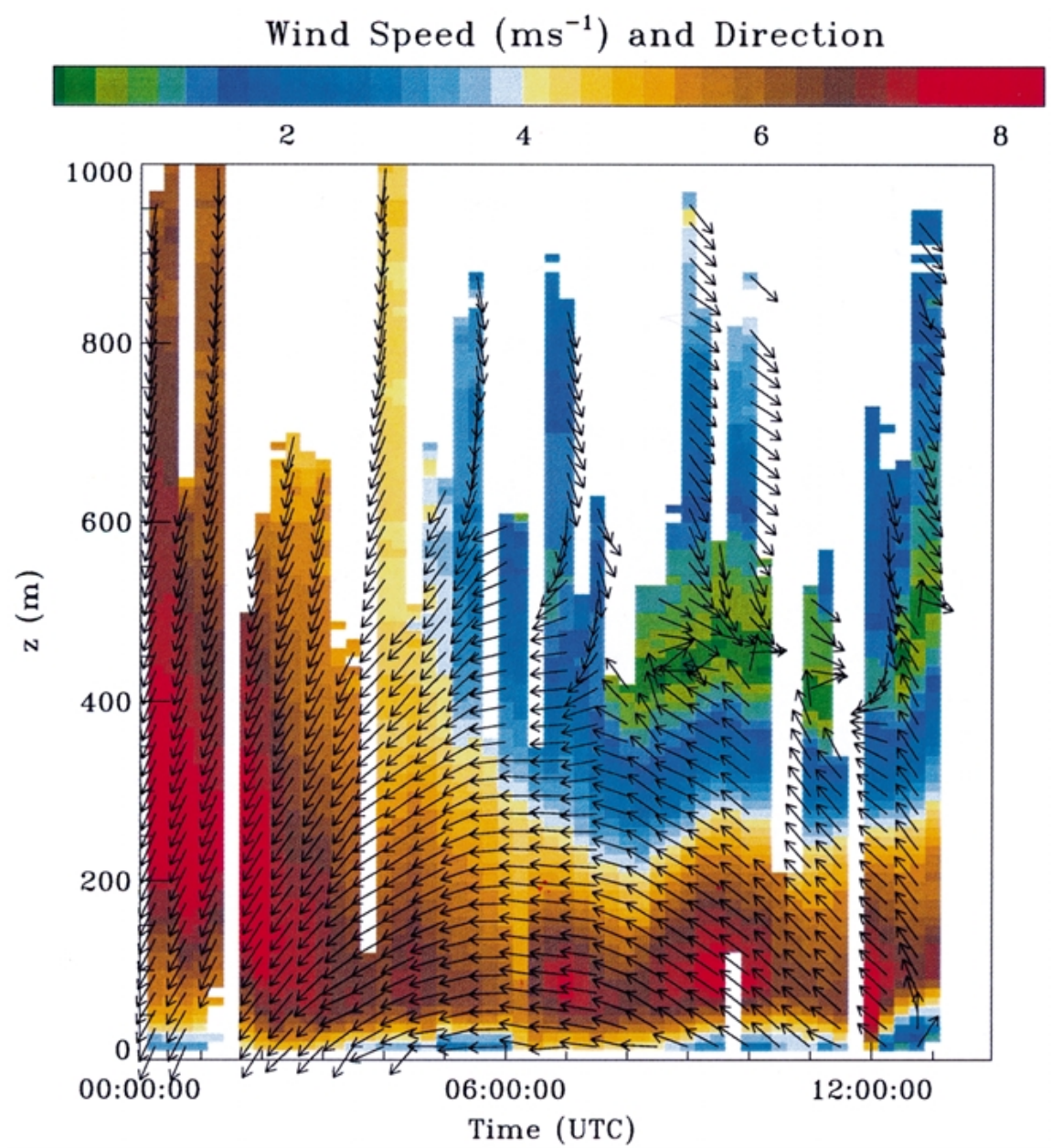

Figure 4. HRDL time-height cross-section of wind speed and direction during the night of 18 October 1999. Each vertical profile is averaged over $30 \mathrm{~min}$.

\subsection{OVERTURNING EDDIES AT THE TOP OF THE DENSITY CURRENT}

At approximately 0140 UTC on 18 October 1999, the air temperature, starting from the upper levels on the 60-m tower, suddenly dropped by up to $2{ }^{\circ} \mathrm{C}$ during a 14 min period (Figure 5). As the temperature rapidly decreased at almost all the levels except near the ground, the temperature above $10 \mathrm{~m}$ oscillated at a period of about $0.7 \mathrm{~min}$ (a frequency of $0.15 \mathrm{~s}^{-1}$ ). Since the observed frequency is higher than the local Brunt Väisälä frequency of $0.02 \mathrm{~s}^{-1}$, the temperature oscillations were forced by eddies, and were not internal gravity waves. After several temperature oscillations, the air temperature, starting from the top level, increased sharply by $\approx 3^{\circ} \mathrm{C}$ at almost all the levels on the 60 -m tower except near the ground, and was 1 to $2^{\circ} \mathrm{C}$ warmer than the temperature before the large drop at each level. Associated 
with the large temperature drop, the humidity and carbon dioxide increased as well (Figure 6).

The downward propagating temperature drop on the night of 18 October indicates that the density current nose passed by the 60-m tower at 0140 UTC. Since humidity and $\mathrm{CO}_{2}$ decrease with height due to evaporation and respiration at the ground under normal stable nocturnal boundary conditions, the sudden increase of $\mathrm{CO}_{2}$ and water vapour, and the oscillation of the air temperature in the upper part of the density current imply that the warm, dry low- $\mathrm{CO}_{2}$ air was pushed under the cold, moist high- $\mathrm{CO}_{2}$ air by overturning eddies generated by the moving density current. These overturning eddies at the top of the density current head were also observed by the FM-CW radar (Figure 7) and the HRDL vertical-slice scans (Figure 8a).

According to Simpson (1969) and Thorpe (1973), strong shear above a density current can lead to Kelvin-Helmoholtz billows as the nose of the density current steadily propagates. The development of the billow is associated with $\mathrm{K}-\mathrm{H}$ instability formed at the interface between two fluids of different densities moving relative to each other. Similar wave disturbances above density currents were also observed from numerical simulations of propagating internal bores by Klemp et al. (1997), from ambient shear flow on density currents by Liu and Moncrieff (1996), and from thunderstorm outflow by Droegemeier and Wilhelmson (1986). Lalas et al. (1976) found that the ground can destabilize K-H waves and lead to instabilities at many wavelengths.

Einaudi and Finnigan (1993) observed similar phenomena around $330 \mathrm{~m}$ at night at the BAO tower, where the potential temperature gradient and the wind shear were strongest. In that case, a large temperature oscillation was observed between 50 and $100 \mathrm{~m}$, with an oscillation period on the order of $10 \mathrm{~min}$. During the CASES-99 event, a similar wind shear layer was observed by HRDL between 100 and $200 \mathrm{~m}$. Therefore, the overturning eddies observed in the upper part of the density current (corresponding to 0140-0146 UTC at $60 \mathrm{~m}$ in the top panel of Figure 5) could be associated with the disturbance generated by the shear flow instability on the density current.

\subsection{TURBULENCE AND THERMAL INSTABILITY}

The overturning eddies generated local thermal instability (Figure 5), with large upward sensible heat flux and downward moisture and carbon dioxide fluxes between about 30 and $50 \mathrm{~m}$ (Figure 9). The direction of this turbulence transport is opposite to the fluxes in the surrounding stable environment. Comparisons between the sonic anemometer data sampled at $1 \mathrm{~s}^{-1}$ and $20 \mathrm{~s}^{-1}$ (not shown) indicate that the counter-gradient fluxes were associated with small eddies and would be missed by slow response instruments. This result is consistent with the conclusions of Mahrt (1985) that turbulence generated by the buoyancy instability within stratified flow 


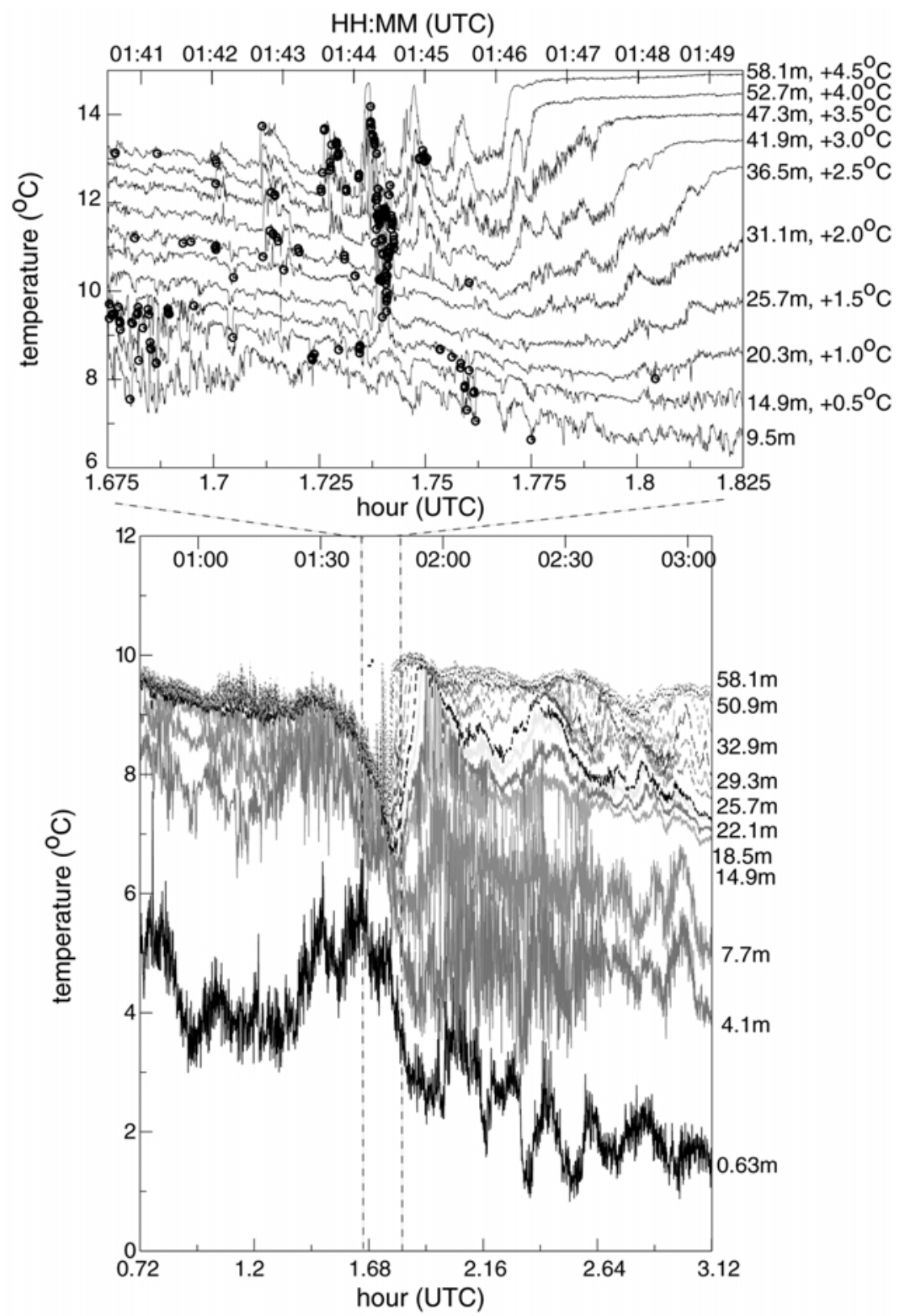

Figure 5. Thermocouple temperatures at selected heights (a subset of all the observation heights, which are labeled at the right end of each time series) during the passage of the density current (bottom panel). The temperature variations are enlarged for the period of the largest temperature decrease during this event (top panel). The black circles in the top panel indicate the time and height when the air temperature was colder than that at $1.8 \mathrm{~m}$ below by at least $0.25^{\circ} \mathrm{C}$, indicating regions of local thermal instability. The time series of temperature in the top panel are shifted by the amount listed in the figure for better viewing of the time and height of the thermally unstable spots. 

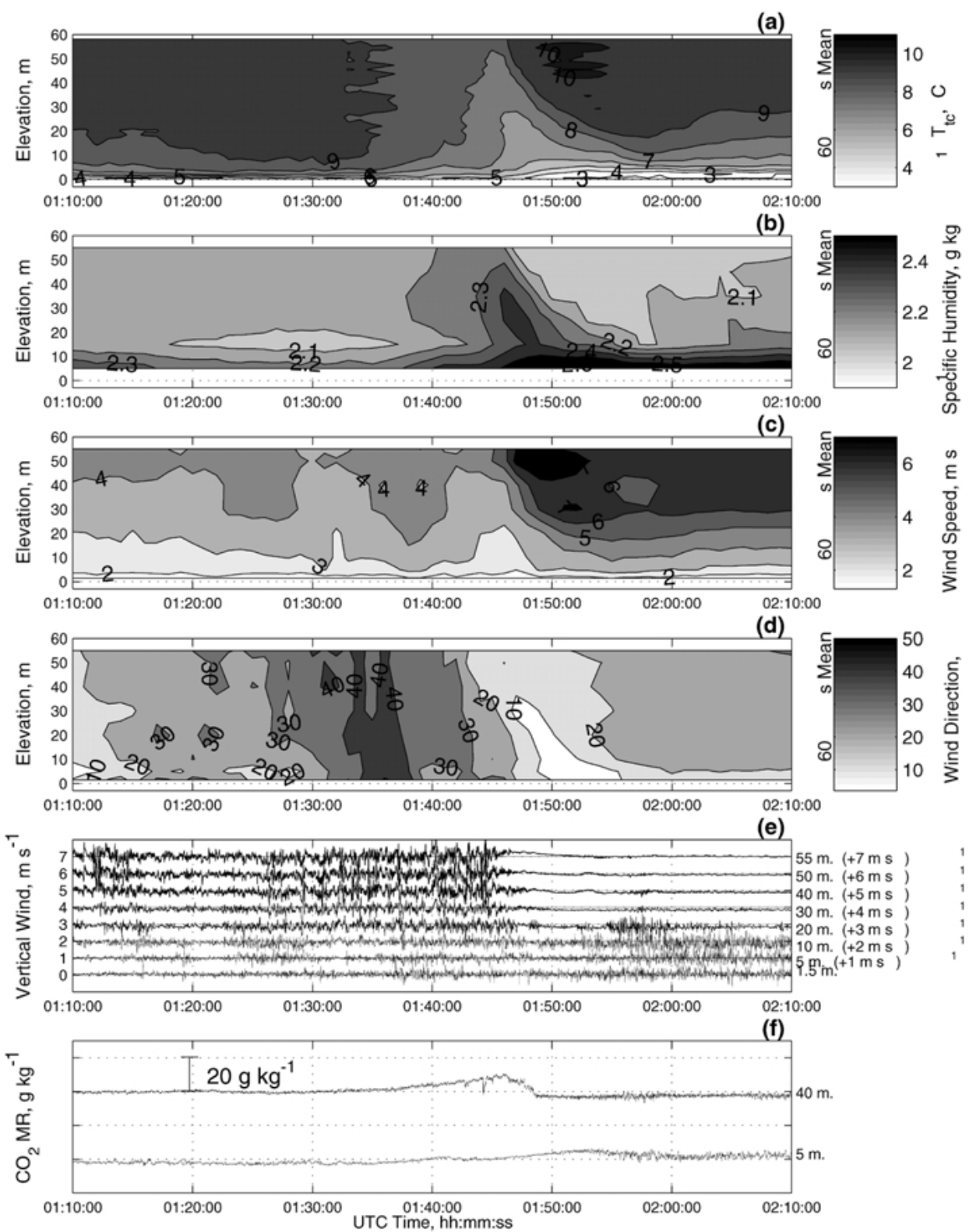

Figure 6. Time-height cross section of (a) air temperature (thermocouples), (b) specific humidity (aspirated Väisälä), (c) wind speed (prop-vanes), (d) wind direction (prop-vanes), (e) vertical velocity (sonic anemometers) at 8 levels on the 60-m tower, and (f) relative variations of carbon dioxide mixing ratio at $5 \mathrm{~m}$ and $40 \mathrm{~m}$ on the $60-\mathrm{m}$ tower during the density current passage. The vertical velocity above $5 \mathrm{~m}$ is shifted by the value on the right side of each time series for better viewing of the time and height of turbulent mixing. 


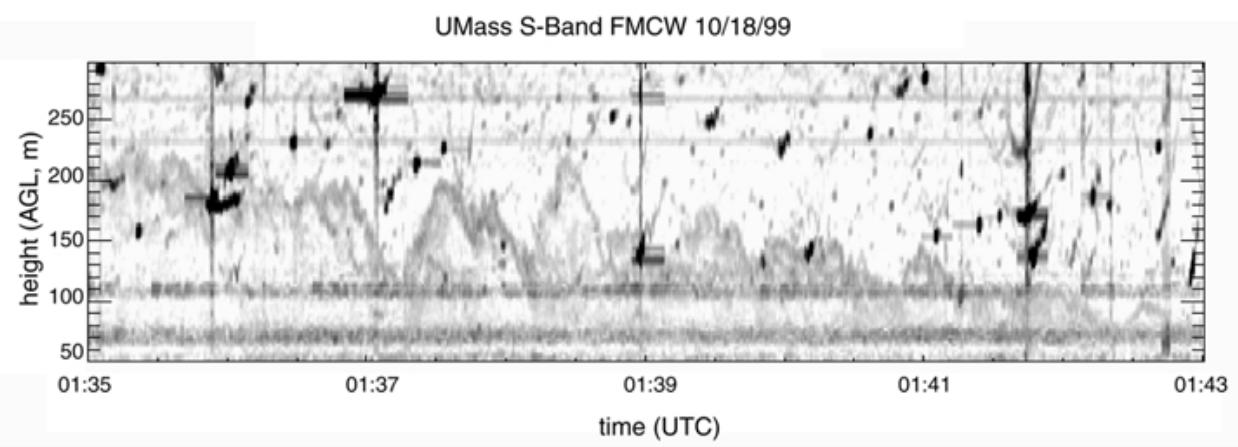

Figure 7. Time-height cross section of the FMCW radar echo beginning at 0135 UTC indicates an interfacial layer initially near $200 \mathrm{~m}$ decreasing to approximately $50 \mathrm{~m}$ eight minutes later. Fluctations in the height of the layer are indicative of large turbulent eddies. Grayscale corresponds to a $30 \mathrm{~dB}$ range of intensities, with the strongest echoes due to insects and/or birds traversing the radar beam. Horizontal bands near $100 \mathrm{~m}$ and below are due to ground clutter.

was characterized by relatively small three-dimensional eddies. The turbulence associated with the thermal instability was strongest at the $55 \mathrm{~m}$ level.

\subsection{TURBULENCE AND SHEAR INSTABILITY}

In order to maintain mass balance, a local secondary circulation occurred as the density current propagated by the 60 - $\mathrm{m}$ tower. The ascending branch resulted from the uplifting of the density current nose. The descending branch produced a sudden temperature increase and strong stratification immediately after the passage of the density current head, which in turn led to a sharp reduction of the turbulent mixing, and a sudden wind speed increase of $2-3 \mathrm{~m} \mathrm{~s}^{-1}$ at almost all the observation levels except near the ground (Figure 9b). As the wind surge propagated down to the ground, strong shear was generated. Since the strongest stratification was close to the ground, the strongest shear-generated turbulence was observed above the lowest sonic anemometer at a level of between $5 \mathrm{~m}$ and $10 \mathrm{~m}$, where the bulk Richardson number was on average less than 0.25 (Figure 10), and diffused upward into the strongly stratified flow generated by the descending flow. The shear-generated turbulence transfer of heat and moisture was even stronger than the thermallygenerated transfer in the upper part of the density current head a few minutes earlier (Figure 9). Within the shear-generated turbulence, some thermally-unstable regions were observed (Figure 5).

During the hour prior to the arrival of the density current, HRDL scans indicated that the northeasterly LLJ maximum of slightly greater than $8 \mathrm{~m} \mathrm{~s}^{-1}$ was between 200 and $250 \mathrm{~m}$ AGL (Figure 4). The strong turbulence mixing related to both thermal and shear instabilities resulted in large downward momentum transport. As a result, the height of the LLJ maximum appeared to have moved downward 

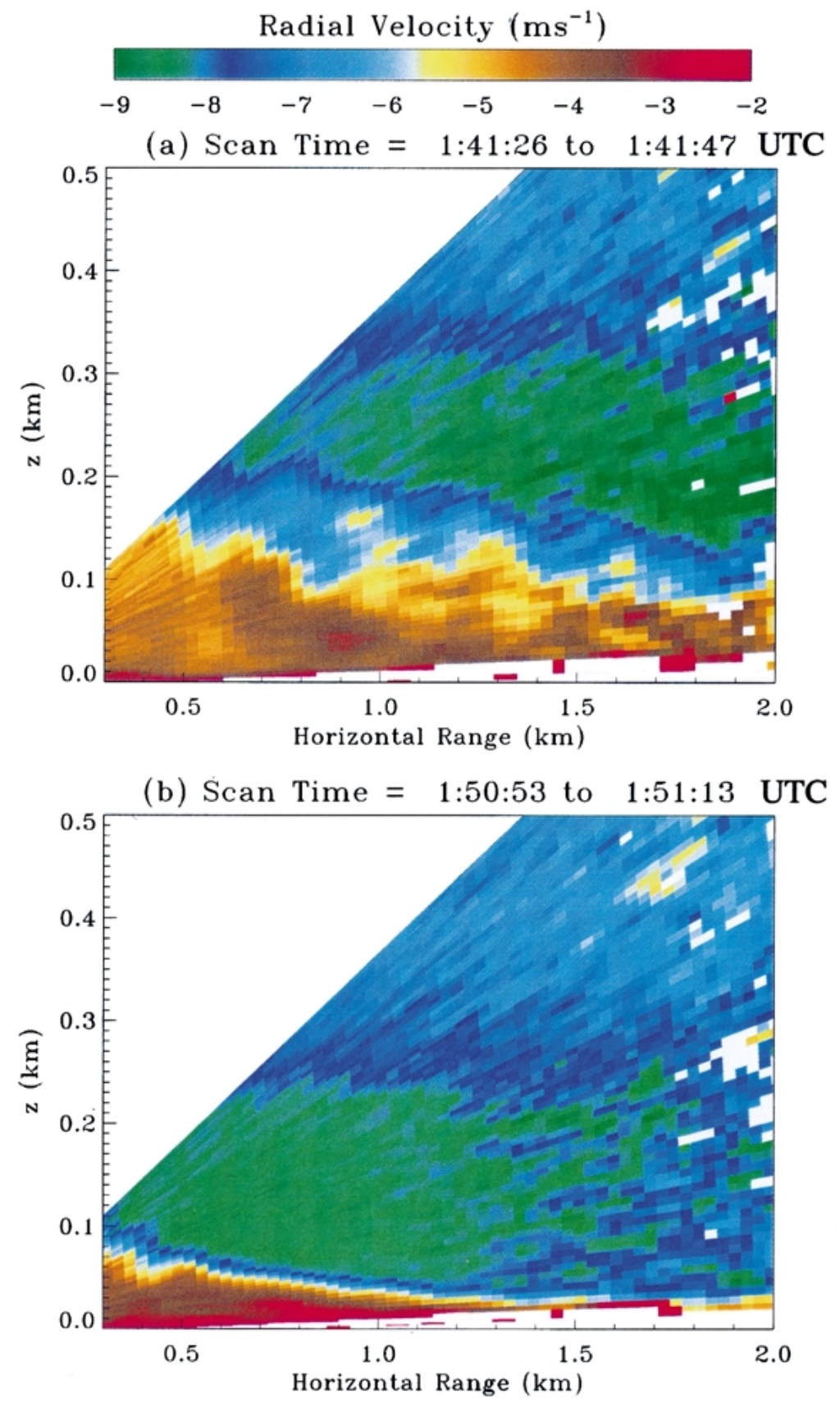

Figure 8. Representative vertical-slice scans of radial velocity recorded by HRDL (a) during and (b) after the passage of the density current head. Scans are toward the ambient flow direction (therefore, the radial velocity is equal to the wind speed) at an azimuth of $30^{\circ}$. The elevation angle was scanned between 0 and $20^{\circ}$ from the ground. Negative radial velocities indicate flow towards the lidar. 

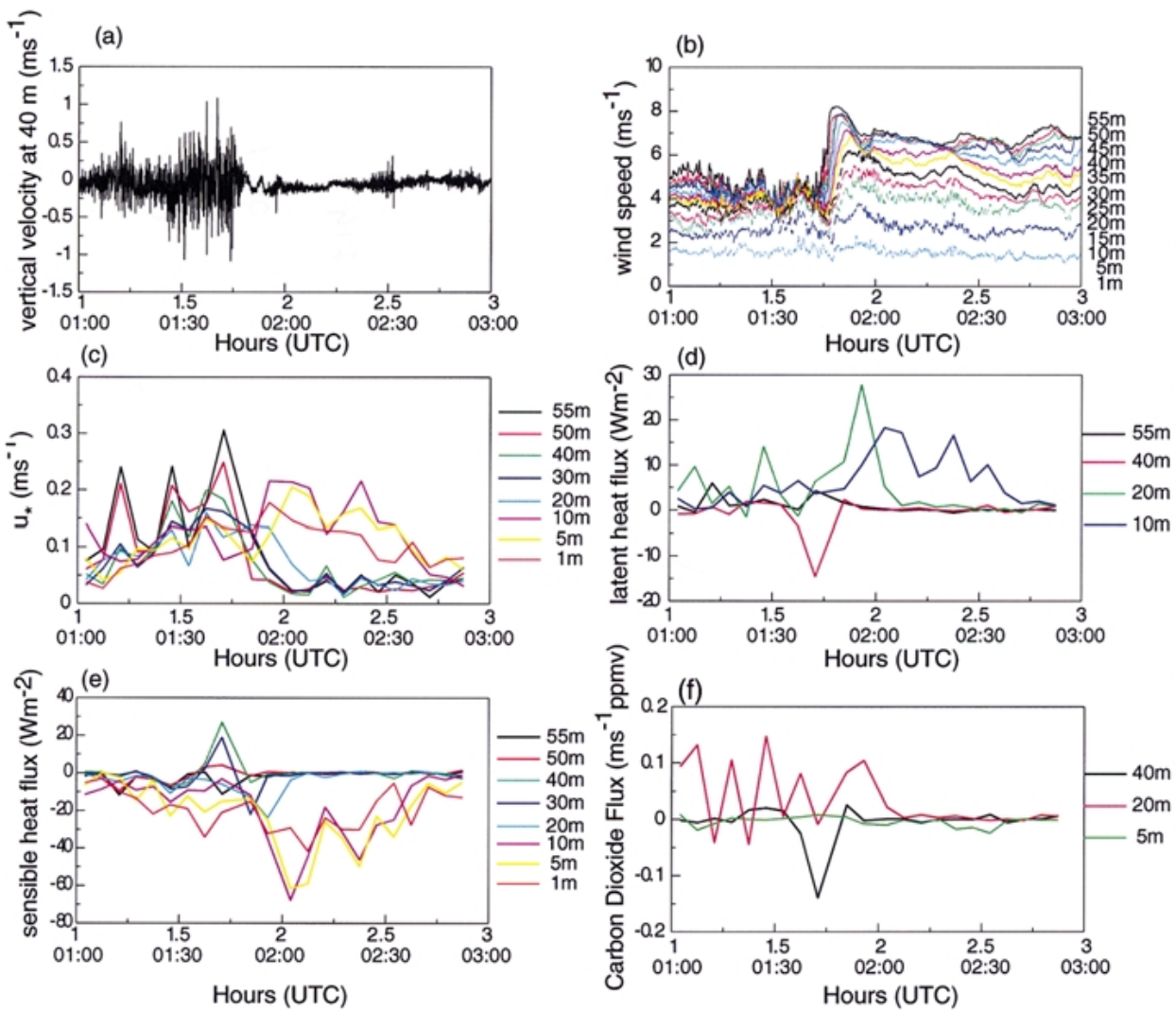

Figure 9. (a) The time series of the vertical velocity at $40 \mathrm{~m}$, (b) the wind speed at various heights on the 60-m tower, and turbulent fluxes of (c) momentum, (d) latent heat, (e) sensible heat, and (f) carbon dioxide during the density current passage.

from $\approx 240 \mathrm{~m} \mathrm{AGL}$ at $0100 \mathrm{UTC}$ to $\approx 130 \mathrm{~m}$ at $0145 \mathrm{UTC}$ (Figure 4, see more details in Banta et al., 2002).

\subsection{PROPAGATION OF THE DENSITY CURRENT}

The wind surge associated with the descending motion following the density current head was also observed by the six ISFF towers at $10 \mathrm{~m}$ (Figure 11). Based on the distances between the six ISFF towers and the timing of the wind surge at each station, the propagation speed and direction of the density current were calculated to be $2.3 \mathrm{~m} \mathrm{~s}^{-1}$ from $47^{\circ}$.

The head of the density current was clearly identified as the triangle-shaped strong backscattering region (light region labeled event I in Figure 12) by the mini-sodars at Beaumont $\left(37.627^{\circ} \mathrm{N}, 96.538^{\circ} \mathrm{W}\right.$, about $17.4 \mathrm{~km}$ ESE of the $60-\mathrm{m}$ tower) and Leon $\left(37.644^{\circ} \mathrm{N}, 96.726^{\circ} \mathrm{W}\right.$, about $1.1 \mathrm{~km} \mathrm{SE}$ of the $60-\mathrm{m}$ tower), Kansas, at 0115 UTC and 0145 UTC, respectively (Figure 12). The head of 


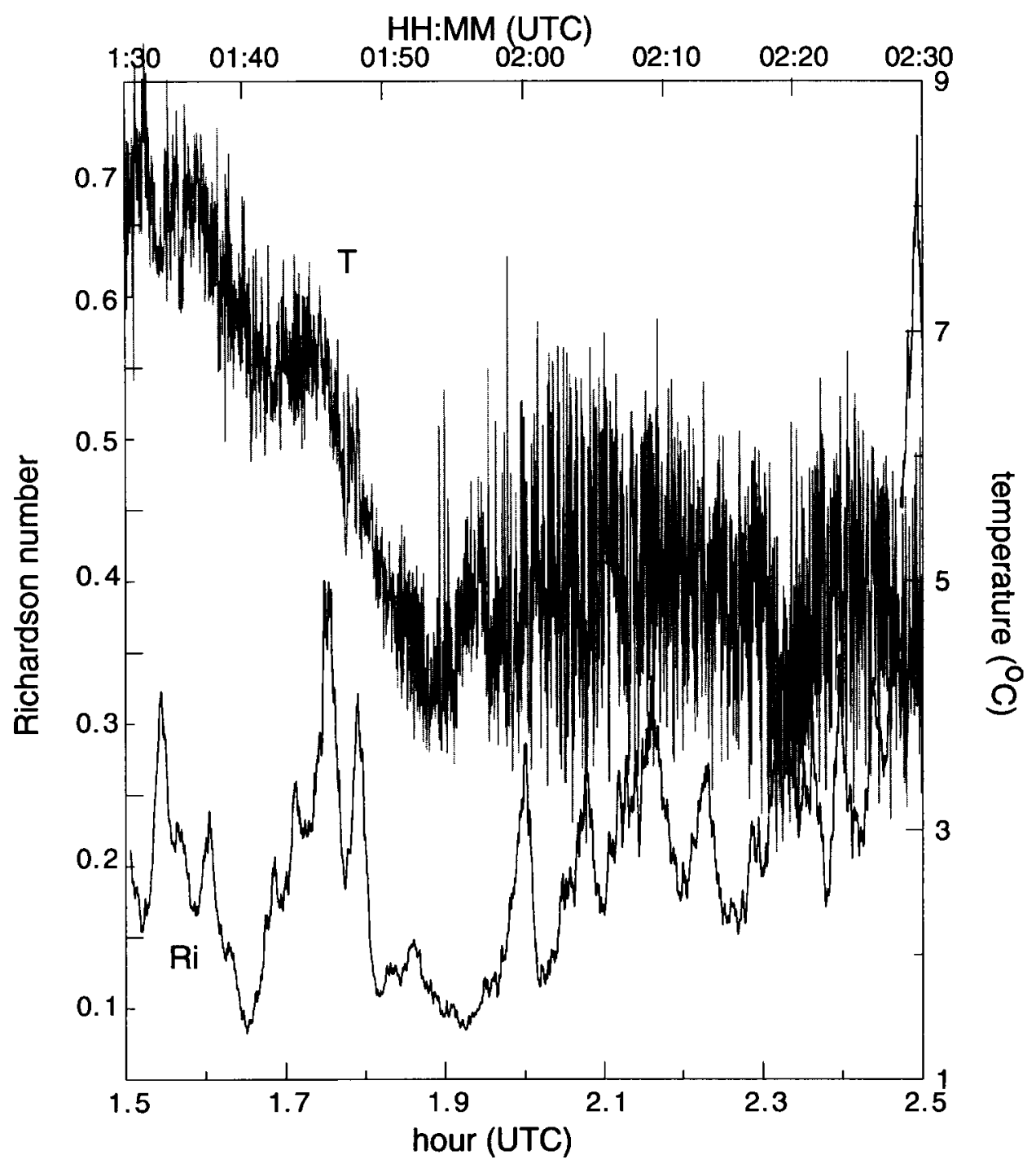

Figure 10. Time series of bulk Richardson number and the thermocouple temperature between 1.5 $\mathrm{m}$ and $5 \mathrm{~m}$. The large temperature fluctuation between 2 and 2.5 UTC indicates strong turbulence within the layer.

the density current extended to about $120 \mathrm{~m}$ height. Based on the sodar observation, and assuming that the density current propagated between Beaumont and Leon in the same direction as it passed the 60-m tower, its propagation speed averaged about $9.4 \mathrm{~m} \mathrm{~s}^{-1}$ between the two locations along the density current propagation direction (Figure 13). This result implies that the density current slowed down as it traveled about $10 \mathrm{~km}$ between Beamount and Leon along the direction of the density current propagation and was at least $10 \mathrm{~km}$ wide. 
$\mathrm{HH}: \mathrm{MM}$ (UTC)

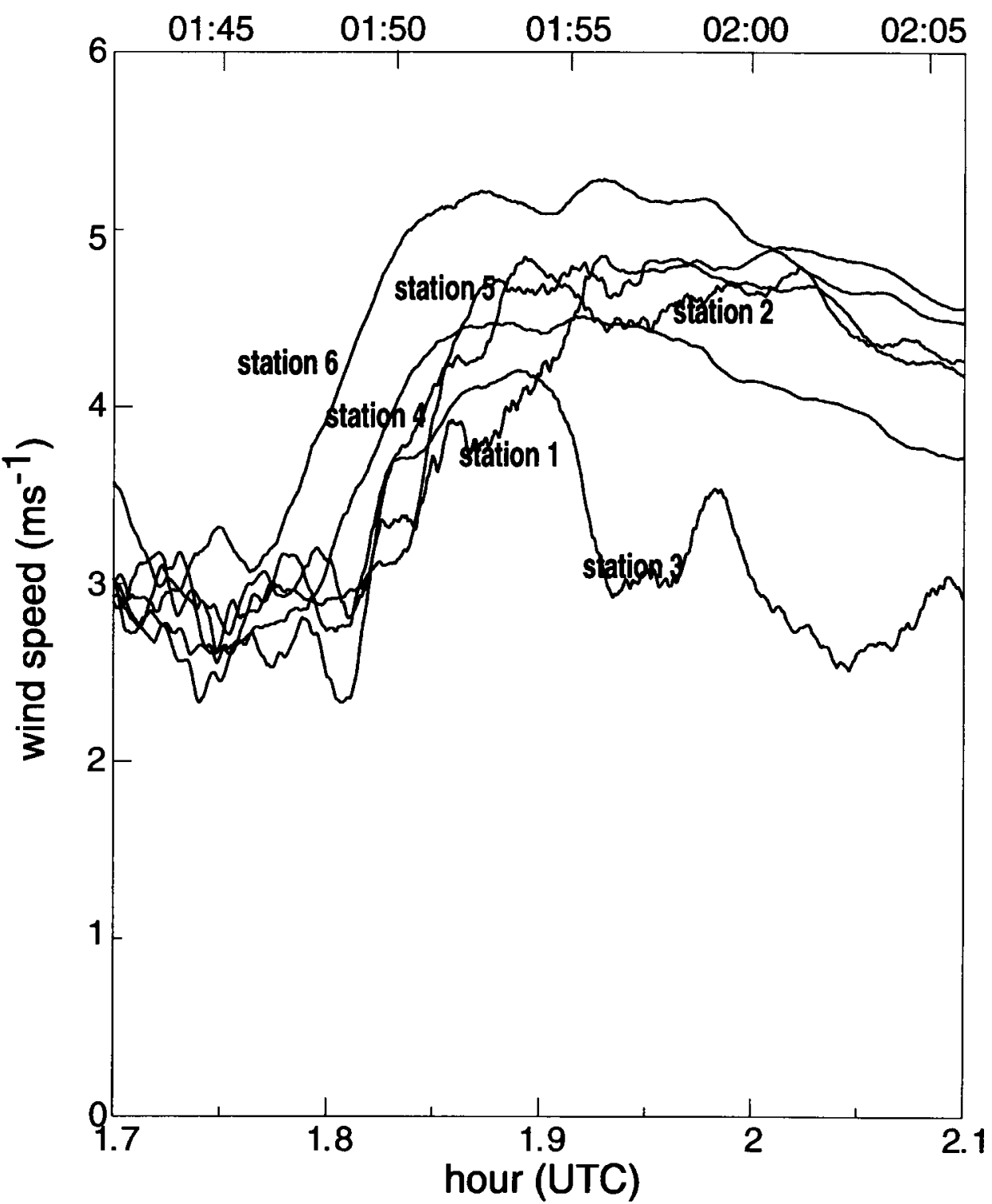

Figure 11. The wind surge observed at the six ISFF towers following the density current head.

According to internal density current theory (Simpson, 1997), the propagation speed $U$, the relative density difference between the density current and the ambient air $\Delta \rho / \rho$, and the height of the density current head $H$ are related by,

$$
U=\left(\frac{\Delta \rho}{\rho} g H\right)^{1 / 2},
$$


Beaumont

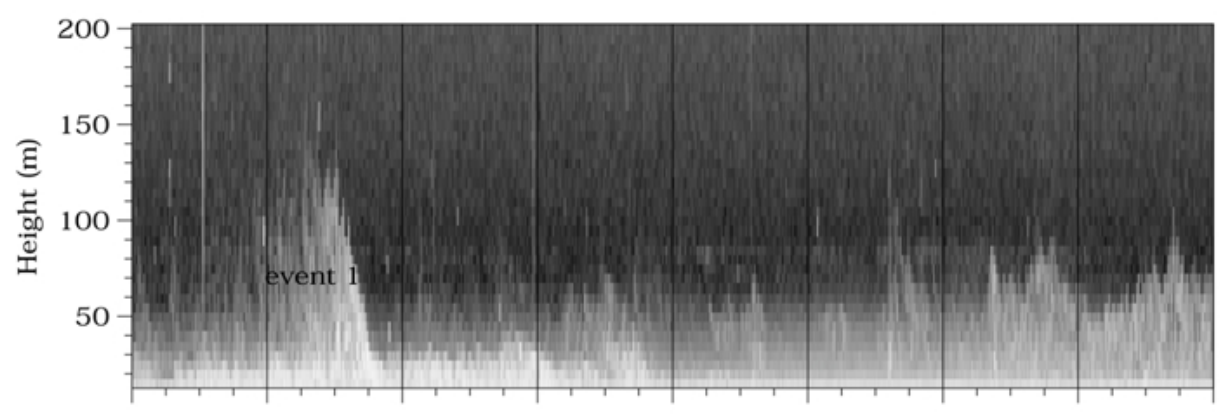

Leon
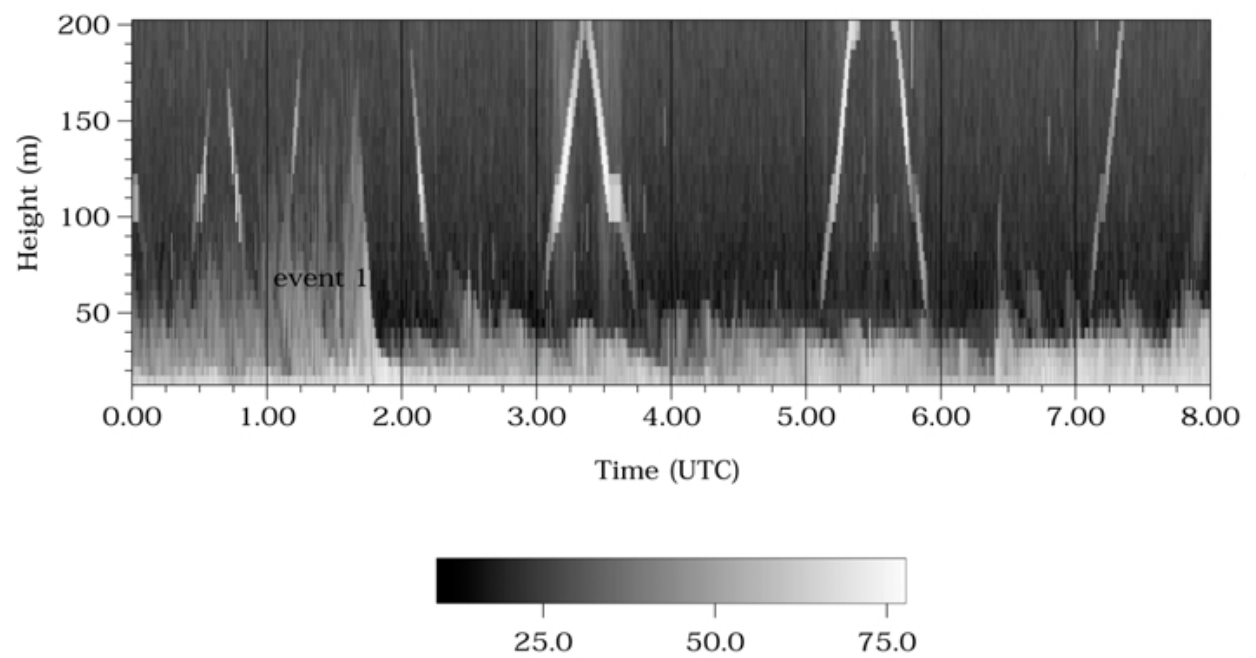

Relative Signal Intensity $(\mathrm{dB})$

Figure 12. Acoustic backscattter from minisodars at Beaumont and Leon showing the density current event near 0130 . The strong signals above $75 \mathrm{~m}$ at Leon at 0300 to 0400 and 0500 to 0600 are reflections from an ascending and descending tethered balloon.

where $g$ is the acceleration of gravity. Assuming $\Delta \rho / \rho \sim-\Delta T / T$, where $T$ is the temperature and $\Delta T$ is the temperature difference between inside and outside of the density current, the observed $\Delta \rho / \rho \sim-\Delta T / T$ is approximately $1.5 / 282.65$. With $U=2.3 \mathrm{~m} \mathrm{~s}^{-1}, H \simeq 102 \mathrm{~m}$, which is close to the mini-sodar observation of $120 \mathrm{~m}$.

During the entire night, the regional surface wind was weak (between 0 and 3 $\mathrm{m} \mathrm{s}^{-1}$ ) and the wind direction varied slowly from southerly to northerly. A weak cold front at the Great Lakes area, a cold front NW of Nebraska, and a warm cloud system south of Kansas existed at the time of the density current passage. The general slope of the regional (about $5-10 \mathrm{~km}$ ) topography is gently tilted downward 


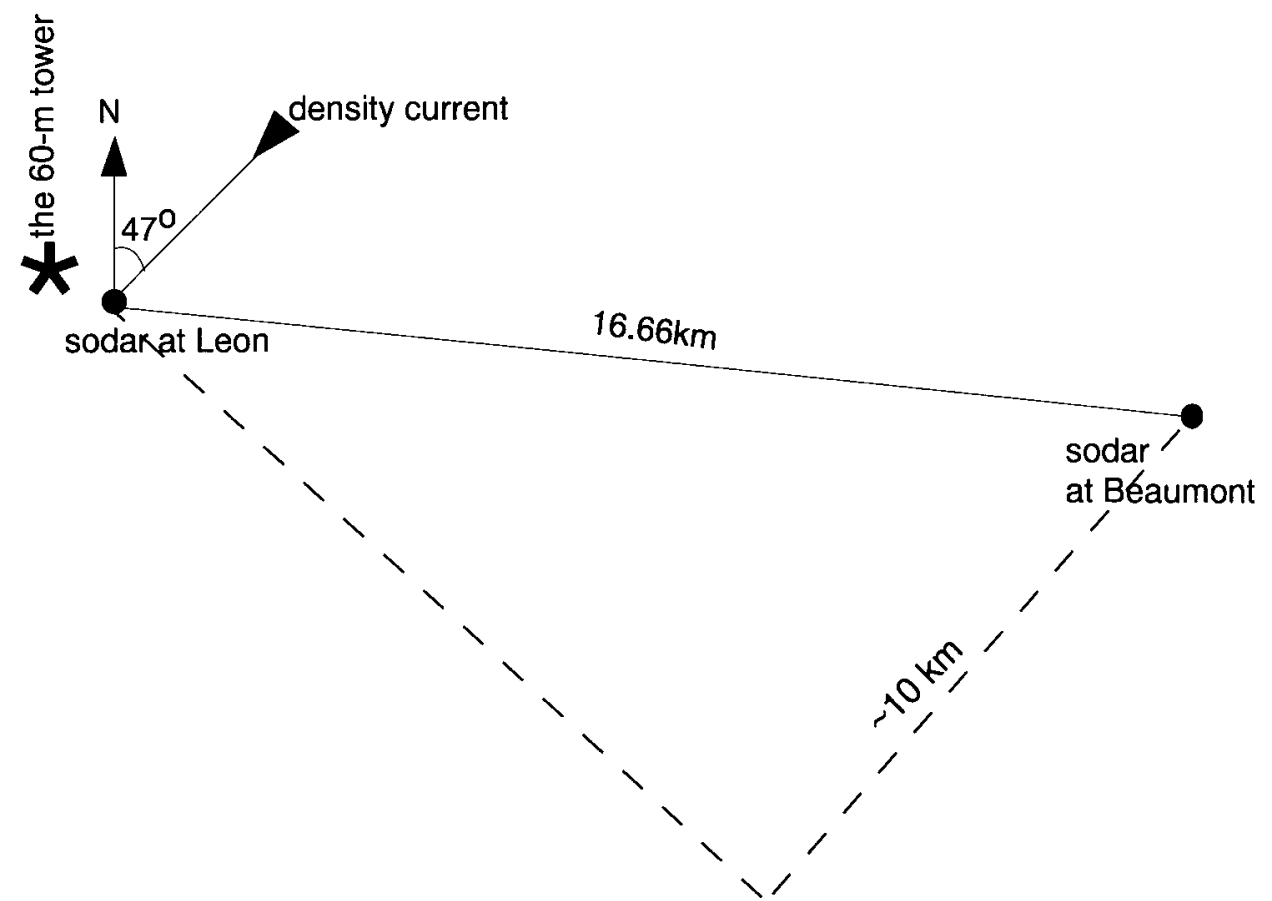

Figure 13. A schematic demonstrating the relative locations of two sodars at Leon and Beaumont, and the derived density current propagation direction.

from northeast to southwest. A ground network in a gully about $1 \mathrm{~km} \mathrm{SSW}$ of the 60-m tower observed drainage flows between 0100 UTC and 0252 UTC when the density current passed the 60-m tower (Mahrt et al., 2001). Nonetheless, the density current clearly had its origin outside of the CASES-99 observation domain and we do not have solid evidence to prove either the cold-front or drainage flow origin.

\section{Summary}

The sequence and the height of the intermittent turbulence, which is shown in Figure 6e, are clearly associated with the passage of the density current. A schematic diagram in Figure 14 summarizes some of the important dynamic features of the density current and their relationships to the turbulence intermittency. Due to the fast propagation of the density current, thermal instability occurred when cold air was pushed above warm air by large-eddy overturning at the top of the density current head. Due to mass conservation, the descending motion following the uplift forced by the density current head led to strong stratification, warmer air, and a sudden wind speed increase. As the wind surge approached the ground, strong shear instability was induced. The turbulent mixing generated by the thermal instability propagated downward. This 'upside down' boundary layer is different from the 
Descending air induced by mass conservation results in warmer air, strong stratification, sudden decrease in the turbulent mixing, and a wind surge.
Overturning eddies force cold air over warm air, leading to thermal instability, which in turn generates turbulent transports in opposite direction to that in the stable boundary layer.

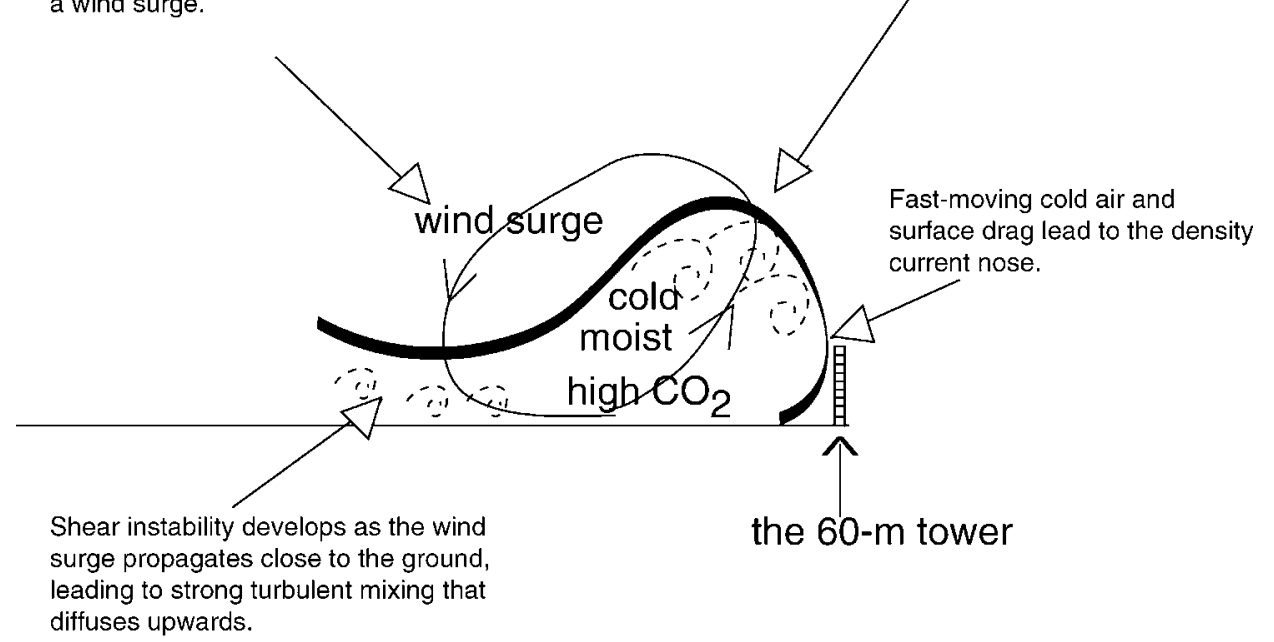

Figure 14. Schematic diagram of the density current.

traditional surface-generated turbulent boundary layer (Mahrt and Vickers, 2002). In addition, turbulent transport of momentum, heat, moisture, and $\mathrm{CO}_{2}$ that were generated by the local thermal instability is opposite in direction to the turbulent transport in a stable boundary layer. The turbulent mixing generated by the shear instability diffused upward until it reached the strong stable layer induced by the descending motion following the density current head. Due to different timing and heights of the thermal and shear instabilities, turbulence observed at a fixed level appears to be intermittent.

We show that the buoyancy-driven turbulence from the large-eddy overturning in the upper part of the density current head may not be able to propagate down to the surface, depending on the stratification of the ambient flow. As the head of the density current passes by, the strong stratification associated with the descending air may prevent the shear-generated turbulence from spreading to higher levels. Therefore, turbulence generated by the overturning eddies at the upper part of the density current head may seem to be elevated for a short period. The vertical variation of the turbulence associated with the sequence of thermal and shear instabilities also implies that a constant surface flux layer does not exist during the passage of the density current.

A large temperature drop resembling the density current in this study was also observed over a dense forest (Sun et al., 1998). The extensive spatial coverage of the CASES-99 observational network established the identity of this intermittent turbulence event, which sheds light on previous nocturnal observations. The density current did not originate within the observational domain of CASES-99, 
therefore we do not know its source. This study demonstrates that the nocturnal boundary layer is strongly affected by mesoscale atmospheric disturbances, and determining their structure and evolution is crucial for understanding their role in generating intermittent turbulence in the nocturnal boundary layer.

\section{Acknowledgements}

We would like to thank Marvin Wesley, David Cook, and David Auble for their contribution to $\mathrm{CO}_{2}$ measurements in CASES-99. JS and SB are supported by U.S. Army Research Office, contract DAAD19-99-1-0320, and NSF grant ATM-9906637. Financial support is provided, in part, to WB by the Atmospheric Sciences Division, Mesoscale Dynamics Program of the National Science Foundation (NSF), and by the Army Research Office (ARO), Mechanical and Environmental Sciences Division, contract DAAD 19-99-C-0037. Funding for HDRL data analysis and field measurements was provided by the Army Research Office under proposal \#40065-EV, the Center for Geosciences/Atmospheric Research at Colorado State University, and the National Science Foundation (Grant \# ATM9908453). Funding for CN is provided by the U.S. Army Research Office. RC was supported by the Department of Energy, Office of Science, Office of Biological and Environmental Research, under contract W-31-109-Eng-18. We would like to thank Larry Mahrt for his valuable comments.

\section{References}

Banta, R. M., Newsom, R. K., Lundquist, J. K., Pichugina, Y. L., Coulter, R. L., and Mahrt, L.: 2002, 'Nocturnal Low-Level Jet Characteristics over Kansas during CASES-99', Boundary-Layer Meteorol. 105, 221-252.

Blumen, W., Banta, R., Burns, S. P., Fritts, D. C., Newsom, R., Poulos, G. S., and Sun, J.: 2001, 'Turbulence Statistics of a Kelvin-Helmholtz Billow Event Observed in the Nighttime Boundary Layer during the CASES-99 Field Program', Dyn. Atmos. Oceans 34, 189-204.

Blumen, W., Grossman, R. L., and Piper, M.: 1999, 'Analysis of Heat Budget, Dissipation and Frontogenesis in a Shallow Density Current', Boundary-Layer Meteorol. 91, 281-306.

Burns, S. P. and Sun, J.: 2000, 'Thermocouple Temperature Measurements from the CASES-99 Main Tower', in 14th Symposium on Boundary Layer and Turbulence, 7-11 August 2000, Snowmass, CO, pp. 358-361.

Cheung, T. K. and Little, C. G.: 1990, 'Meteorological Tower, Microbarograph Array, and Sodar Observations of Solitary-Like Waves in the Nocturnal Boundary Layer', J. Atmos. Sci. 47, 25162536.

Coulter, R. L. and Martin, T. J.: 1986, 'Results from a High Power, High Frequency Sodar', Atmos. Res. 20, 257-270.

Doran, J. C. and Horst, T. W.: 1981, 'Velocity and Temperature Oscillations in Drainage Winds', $J$. Appl. Meteorol. 20, 360-364.

Droegemeier, K. K. and Wilhelmson, R. B.: 1986, 'Kelvin-Helmholtz Instability in a Numerically Simulated Thunderstorm Outflow', Bull. Amer. Meteorol. Soc. 67, 416-417. 
Einaudi, F. and Finnigan, J. J.: 1993, 'Wave-Turbulence Dyanmics in the Stably Stratified Boundary Layer', J. Atmos. Sci. 50, 1841-1864.

Einaudi, F., Bedard Jr., A. J., and Finnigan, J. J.: 1989, 'A Climatology of Gravity Waves and Other Coherent Disturbances at the Boulder Atmospheric Observatory during March-April 1984', J. Atmos. Sci. 46, 303-329.

Emanuel, K. A.: 1983, 'On the Dynamical Definitions of "Mesoscale", , in D. K. Lilly and T. GalChen (eds.), Mesoscale Meteorology-Theories, Observations and Models, Reidel, Dordrecht, pp. 1-12.

Etling, D.: 1990, ‘On Plume Meandering under Stable Stratification', Atmos. Environ. 24A, 1979_ 1985.

Finnigan, J. J.: 1988, 'Kinetic Energy Transfer between Internal Gravity Waves and Turbulence', J. Atmos. Sci. 45, 486-505.

Finnigan, J. J., Einaudi, F., and Fua, D.: 1984, 'The Interaction between an Internal Gravity Wave and Turbulence in the Stably-Stratified Nocturnal Boundary Layer', J. Atmos. Sci. 41, 2409-2436.

Fulton, R., Zrnic, D. S., and Doviak, R. J.: 1990, 'Initiation of a Solitary Wave Family in the Demise of a Nocturnal Thunderstorm Density Current', J. Atmos. Sci. 47, 319-337.

Grund, C. J., Banta, R. M., George, J. L., Howell, J. N., Post, M. J., Richter, R. A., and Weickmann, A. M.: 2001, 'High-Resolution Doppler Lidar for Boundary Layer and Cloud Research', J. Atmos. Oceanic Tech. 18, 376-393.

Howell, J. and Sun, J.: 1999, 'Surface Layer Fluxes in Stable Conditions', Boundary-Layer Meteorol. 90, 495-520.

Ince, T., Pazmany, A. L., Frasier, S. J., and McIntosh, R. E.: 1998, 'A High Resolution FM-CW SBand Radar for Boundary Layer Profiling and Cloud Applications', in Proceedings of the 1998 Battlespace Atmospherics Conference, Hanscom AFB, MA, December 1-3, 1998, pp. 432-439.

Klemp, J. B., Rotunno, R., and Skamarock, W. C.: 1997, 'On the Propagation of Internal Bores', J. Fluid Mech. 331, 81-106.

Lalas, D. P., Einaudi, F., and Fua, D.: 1976, 'The Destabilizing Effect of the Ground on KelvinHelmholtz Waves in the Atmosphere', J. Atmos. Sci. 33, 59-69.

Liu, C.-H. and Moncrieff, M. W.: 1996, 'A Numerical Study of the Effects of Ambient Flow and Shear on Density Currents', Mon. Wea. Rev. 124, 2282-2303.

Lu, Nai-Ping, Neff, W. D., and Kaimal, J. C.: 1983, 'Wave and Turbulence Structure in a Disturbed Nocturnal Inversion', Boundary-Layer Meteorol. 26, 141-155.

Mahrt, L.: 1985, 'Vertical Structure and Turbulence in the Very Stable Boundary Layer', J. Atmos. Sci. 42, 2333-2349.

Mahrt, L.: 1999, 'Stratified Atmospheric Boundary Layers', Boundary-Layer Meteorol. 90, 375-396.

Mahrt, L. and Larsen, S.: 1982, 'Small Scale Drainage Front', Tellus 34, 579-587.

Mahrt, L. and Vickers, D.: 2002, 'Contrasting Vertical Structures of Nocturnal Boundary Layers', Boundary-Layer Meteorol. 105, 351-363.

Mahrt, L. Vickers, D., Nakamura, R., Sun, J., Burns, S., Lenschow, D., and Soler, M. R.: 2001, 'Shallow Drainage and Gully Flows', Boundary-Layer Meteorol. 101, 243-260.

Nappo, C. J.: 1991, 'Sporadic Breakdowns of Stability in the PBL over Simple and Complex Terrain', Boundary-Layer Meteorol. 54, 69-87.

Newsom, R. K. and Banta, R. M.: 2002, 'Shear Instability Gravity Waves in the Stable Nocturnal Boundary Layer as Observed by Doppler Lidar during CASES-99', J. Atmos. Sci., in press.

Poulos, G. S., Blumen, W., Fritts, D. C., Lundquist, J. K., Sun, J., Burns, S. P., Nappo, C., Banta, R., Newsome, R., Cuxart, J., Terradellas, E., Balsley, B., and Jensen, M.: 2002, 'CASES-99: A Comprehensive Investigation of the Stable Nocturnal Boundary Layer', Bull. Amer. Meteorol. Soc. 83, 555-581.

Simpson, J. E.: 1969, 'A Comparison between Laboratory and Atmospheric Density Currents', Quart. J. Roy. Meteorol. Soc. 95, 758-765. 
Simpson, J. E.: 1997, Gravity Currents in the Environment and the Laboratory, Cambridge University Press, 244 pp.

Sun, J., Jensen, N. O., Hummelshoej, P., Jorgensen, H., Mahrt, L., and Chen, Z.: 1998, 'Study of Forest-Atmospheric Interactions over a Beech Forest', in 23rd Conference on Agricultural and Forest Meteorology, November 2-6, 1998, Albuquerque, NM, p. 47.

Thorpe, S. A.: 1973, 'Experiments on Instability and Turbulence in a Stratified Shear Flow', J. Fluid Mech. 61, 731-751.

Wulfmeyer, V., Randall, M., Brewer, W. A., and Hardesty, R. M.: 2000, '2 mm Doppler Lidar Transmitter with High Frequency Stability and Low Chirp’, Opt. Lett. 25, 1228-1230. 